\title{
Contents of Next Issue of Opticheskii Zhurnal (Journal of Optical Technology)
}

DOI: $10.1134 / \mathrm{S} 0030400 \mathrm{X} 11030052$

The following papers will be published in the March issue of Opticheskii Zhurnal (Journal of Optical Technology), Vol. 78, No. 3, 2011.

Physical Optics. Spectroscopic and Thermodynamic Study of Heavy Water (T.V. Voronina and A.A. Slobodov).

Computation, Design, and Manufacture of Optical Systems. Errors in Manufacture and Mounting of Reflection Prisms (V.A. Zverev, E.S. Rytova, and I.N. Timoshchuk); A Catadioptric Retroreflector (A.D. Tsvetkov).

Holography. The Use of Atomic Force Microscope to Determine Short-Wavelength Limit of Applicability of Optical Relief-Phase Holographic Elements Due to Their Surface Roughness (S.N. Koreshev and Yu.V. Altygina).

Optical Instrumentation and Technology. Specific Features of Instrumental Function of Misaligned Fourier-Transform Spectrometer (B.E. Moshkin, S.V. Maksimenko, A.V. Shakun, and L.V. Zasova);
Optimization of Video Signal That Shapes Parameters of Two-Channel TV Pyrometer (A.V. Kuznetsov).

Optical Materials Science and Technology. Methods of Producing and the Properties of Liquid Crystal Orienting Layers Based on Amorphous Carbon (E.A. Konshina); A Method for Enhancing Sensitivity of a Fiber Optic Hydrophone (V.A. Arteev, A.V. Kulikov, I.K. Meshkovskii, and V.E. Strigalev); Methods for Calibrating Prisms with Uncoated Faces Using a Dynamic Goniometer (M.S. Nikolaev and Yu.V. Filatov); Allowance for Influence of Scanning Slit Width of Spectrometers during Measuring Optical Parameters of Tunable Narrow-Band Filters (M.Kh. Azamatov, Sh.Sh. Valeev, I.S. Gainutdinov, and I.Kh. Nagimov).

Practical Manufacturing Problems. A Device for Interferometric Plate Wedging Measuring (B.E. Moshkin and S.V. Maksimenko).

Compiled by L.V. Enushevskaya Translated by S. Belov 